\title{
Culture in ESL Instruction: An Analytic Framework
}

Mark James

The English-as-a-second-language (ESL) classroom for adult immigrants in Canada is often culturally diverse. From an instructional perspective, the role of culture can be complicated. This article presents a framework for examining culture in an ESL instructional context. An explanation of the rationale behind the framework is followed by a description of the way the framework was applied to the LINC Curriculum Guidelines (Citizenship and Immigration Canada, Ontario Region, 1997) to test its usability as an analytical tool. Suggestions are made for directions for further research.

\section{Introduction}

A national census in 1991 revealed that $16 \%$ of the Canadian population (4.3 million people) were not born in Canada. Many of these people came to Canada from countries where the dominant language was not English or French: Of recent immigrants (people who arrived in Canada between 1981 and 1991), 48\% were born in Asia, 25\% in Europe, $10 \%$ in Central or South America, $6 \%$ in the Caribbean, $6 \%$ in Africa, $4 \%$ in the United States, and 1\% in Oceania (Statistics Canada, 1991).

For immigrants who have limited English or French skills, settlement in Canada can be particularly demanding because it involves getting used to not only a new physical environment and culture, but also a new language. Fortunately, this process can be facilitated through settlement programs. A well-known example is the LINC (Language Instruction for Newcomers to Canada) program, which was announced as part of the federal government's language training policy in 1992.

The group targeted by programs like LINC may be characterized by a shared need to develop English language skills. However, the immigration statistics above indicate that it is also characterized by cultural diversity. Classes for adult ESL learners in Canada often reflect this diversity. In some cases as many different cultures may be represented in a classroom as there are students.

Dealing with culture in this context can be complicated. First, culture is not limited to that of the learners, but also includes that of the instructors and program providers, as well as the broader society. Also, simply understanding the concept of culture can be difficult. This is illustrated by the trouble an 
instructor may face trying to answer the student who asks, "What is Canadian culture?"

An analytic framework for culture in ESL instruction (Figure 1) may help in dealing with culture in the context of Canadian ESL programs for adults. The framework presented in this article may be of interest to instructors, curriculum writers, program directors, and researchers who want to consider the way culture is addressed in such programs.

The proposed framework includes three components that contribute to the way culture is addressed in an ESL program.

Balancing a focus on the learners' cultures with a focus on the L2 culture.

The dominant perspective in many branches of the field of L2 education was traditionally a linguistic one, with a focus on the formal aspects of language (e.g., grammar rules). However, as researchers became more aware of and interested in the relationship between culture, language, and language learning, this perspective expanded in different ways:

1. Sociolinguists began looking at context and the way language is actually used. Stern (1983) reviewed the research in this area and pointed out that one of the results was the popularization of functional syllabuses in language teaching: Instead of building a syllabus around abstract grammar points like verb tenses or articles, contexts were added, and the building blocks of syllabuses became functions like "asking for help" or "offering an opinion."

2. Culture became a primary concern for psycholinguists. In their influential study of the effects of attitudes on L2 learning, Gardner and Lambert (1959) suggested that a positive attitude toward the speakers of the L2 and their culture was positively related to motivation and

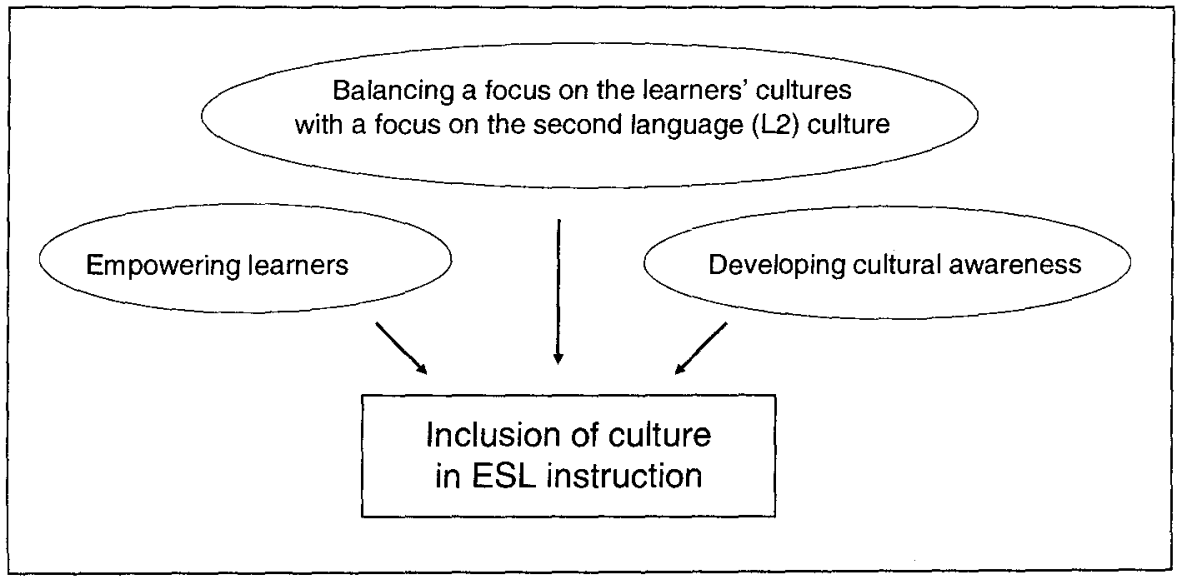

Figure 1. Analytic framework for culture in ESL instruction. 
success in learning the L2. This was fertile ground for research and debate during the next three decades (see Gardner, 1985, for a summary of research in this area).

From both of these perspectives the culture of primary interest was that associated with the target language. However, with the rise of humanistic approaches (e.g., learner-based teaching), the focus shifted to the learners. From this perspective learners are seen as individuals who bring a variety of relevant and valuable background experiences with them to the classroom. The rationale for such an approach is that the learning process will be more relevant and deeply felt, and therefore of a higher quality, if this background knowledge and experience of learners is tapped (Campbell \& Kryszewska, 1992). Usually, when an ESL instructor taps into the background knowledge and experience of an adult ESL learner, he or she will also be tapping into the learner's culture.

The benefit of doing this can be illustrated by research on reading. Schema theory suggests that the background knowledge and experience of a reader has an impact on the way a text is interpreted. The easiest way to understand this is with an example (from Tierney \& Pearson, 1985, cited in James, 1987):

The men were at bat against the bowlers. They did not show any pity. The bowlers placed their men in slips. They placed their men in covers. It did not help. The batsmen hit a lot of fours. They hit some sixes. No ball hit the stumps. No ball was caught. (p. 179)

Linguistically this text is not demanding. However, even for a fluent speaker of English it makes little sense unless the reader is familiar with the sport of cricket. From the perspective of culture, then, an ESL learner from Sri Lanka-where cricket is a popular sport-will probably have an easier time understanding this paragraph than an ESL learner from somewhere like Lebanon, where cricket is not played.

Awareness of and attention to learners' cultures in the multicultural ESL classroom helps instructors to activate prior knowledge as well as to know when and how to build background knowledge. According to Cummins (1996), this is important because

some students may have relevant information in their [first language] but not realize there is any connection with what they are learning in their L2 ... [whereas in] other cases, there may be a considerable cultural gap between what is assumed by the text and what students know from their prior experience. (p. 76)

Cummins suggests the benefits of activating prior knowledge and building background knowledge include the following:

- a more efficient learning process; 
- stimulation for students to use the target language;

- the chance for teachers to get to know their students;

- greater student investment in the learning process as a result of a classroom context in which students' cultural knowledge is expressed, shared, and validated.

It is apparent that both the L2 culture and the learners' cultures are relevant to the L2 learning process. The balance between them is, therefore, an important consideration for the ESL instructor or program designer.

\section{Developing cultural awareness.}

Another perspective has to do with the kind of cultural information that is included in an ESL program and the way it is presented. For example, lessons or units can be limited to superficial information on cultural festivals, holidays, clothes, and food. In contrast a more challenging approach would be to examine the values and beliefs behind daily life. Looking at culture in a deeper way like this can help raise learners' general cultural awareness. Such an awareness would be of value to participants in a society as culturally diverse as Canada.

Moran (Scanlon, 1998) presented an L2 instructional framework that instructors can use to help learners develop this kind of cultural understanding. Learners begin by studying surface-level facts (e.g., history or geography) about another culture. They move on to question the various ways things are done in that culture (e.g., greetings), and then think about the reasons why those things may be done a particular way. At the end of this process they reflect on their own culture. The rationale behind this framework is that "if learners have a strong sense of themselves as members of a culture and understand their own values, they may be better able to adapt to or accept another culture" (p. 76).

Consideration of culture from a deep level has also been advocated in mainstream education, where Banks (1998) has presented a description of levels of curriculum reform. He argues that most school districts fall at the first, or contributions, level. At this level curriculum reform is minimal: The mainstream curriculum remains unchanged, and superficial facts (e.g., historical figures, celebrations) from different cultures are simply factored in. At the second level (ethnic additive), a wider variety of cultural material appears in the curriculum; however, this material is still viewed from the mainstream perspective, and the structure of the curriculum is unchanged. According to Banks, it is not until the third (transformative) and fourth (decision-making and social action) levels that students are able to view curricular content from several perspectives and are encouraged to think critically in relation to social problems. For ESL instructors, and in particular curriculum designers, it is helpful to see in this way the different depths to which culture can be explored in a curriculum. 
This kind of deeper understanding of culture is valuable for both ESL learners and instructors who are concerned with the development of communication skills. According to Condon and Yousef (1975), cultural values and beliefs are one of the three main cultural influences on communication. Both values (i.e., things that are judged good or bad) and beliefs (i.e., things that are judged true or false) can differ widely between cultures. For example, whereas individualism and youth may be valued in one culture, interdependence and age may be valued in another. Not understanding these differences can lead to problems when communication occurs across cultures. This is particularly important for ESL learners and instructors, for whom communication is often cross-cultural.

\section{Empowering learners.}

Finally, it is important to ask what cultural messages are being communicated, either implicitly or explicitly, during the instructional process. This begins with an understanding of power relations and seeing the classroom as a kind of microcosm of broader society, representing both its ideology and its power structure. For example, things like the location of and support for ESL programs can tell a lot about society's view and expectations of immigrants. Curriculum content can also be revealing. For example, in "survival" English courses, the emphasis is often placed on "the way we do things here." In such a case the goal is not really survival; it is assimilation (Auerbach, 1995). A unit on housing, for example, may include things like students' responsibilities as tenants; absent, however, may be things like tenants' rights or what to do when a landlord does not fulfill obligations. This is alarming when one considers that refugees may be particularly susceptible to living in poor housing conditions with excessive rent and can be the victims of harassment.

A participatory approach in L2 education can enable learners to examine critically the social order and become active in shaping their own role in it (Auerbach, 1995). For ESL learners this would mean learning English that is contextualized in (a) their own experiences, and (b) their need to solve real-life problems and conflicts. For example, if the instructional theme is shopping, lessons might revolve around problems students have had as consumers and ways to deal with those problems, such as asking to speak to a shop manager, expressing dissatisfaction, or writing a formal letter of complaint. In the real world these skills may be just as important and relevant as learning how to ask to try something on and to pay for it.

Besides curriculum content, issues such as language choice in L2 programs can reflect power, relations. As the bilingual education debate in California illustrates, this issue can be contentious. English-only policies have often been justified in the following way:

Adult ESL students need to learn English as quickly as possible for survival reasons; the more they are exposed to English, the more quickly 
they will learn; as they hear and use English, they will internalize it and begin to think in English; the only way they will learn it is if they are forced to use it. (Auerbach, 1995, p. 25)

However, Auerbach points out that research shows that a bilingual model of instruction-in which the first language (L1) is used systematically-may be more effective for L2 learners, especially when they are at a lower level or when literacy is an issue. Therefore, English-only policies probably involve deeper political and power issues.

In summary, culture in the ESL context can be viewed in terms of (a) the balance between a focus on the learners' cultures and a focus on the L2 culture, (b) the development of cultural awareness, and (c) the empowerment of learners. Consideration of these perspectives can benefit both ESL learners and instructors.

\section{Applying the Framework to the LINC Curriculum Guidelines}

In order to validate the proposed framework, it was applied to the LINC Curriculum Guidelines (Citizenship and Immigration Canada, Ontario Region, 1997). The LINC program was chosen as an example because: (a) it is a well-known reference point for adult ESL educators across Canada; and (b) it has a readily available, well-developed set of curriculum guidelines. These curriculum guidelines, which are distributed to LINC providers (e.g., boards of education, multicultural centers, YMCAs), contain the suggested content-in the form of instructional goals and objectives--for LINC classes, as well as activities, assessment tools, and descriptions of recommended teaching procedures.

A complete picture of the way culture is addressed in any ESL program would require, among other things, classroom observations and interviews with teachers and students. The purpose of this analysis is not to provide a complete picture; it is to examine the application of the analytic framework described above. The framework may eventually be suitable as a basis for gathering different kinds of data in larger scale investigations.

Two parts of the LINC Curriculum Guidelines were studied: (a) the introductory section, which provides background to the instructor; and (b) the topical units, which provide instructional content and procedures. Findings are presented and discussed under these headings.

\section{Introductory Section}

The introductory section of the LINC Curriculum Guidelines describes the structure and development of the guidelines, the philosophy behind their development, and suggestions for procedures in implementation. Applying the analytic framework to this section reveals the following information. 
Balance a focus on the learners' cultures with a focus on the L2 culture. Attention to Canadian culture is immediately apparent. The primary goal, communicative competence, is described as having four components, one of which is sociocultural competence. In this case sociocultural competence "involves understanding the social context or significance of language use (e.g., recognizing levels of politeness or hidden meanings or performing different language functions effectively, such as interrupting, disagreeing or ending a conversation)" (Citizenship and Immigration Canada, Ontario Region, 1997, p. 10). In other words, learners will be focusing on the ways English is used by Canadians in Canadian society.

The focus on Canadian culture is also clear in the description of the lists of Global Outcomes that are at the center of each of the three LINC levels. The Global Outcomes are intended to "provide learners with concrete skills as well as general social knowledge and coping skills, so that learners become effective social participants," and aim to "ensure that LINC learners acquire sufficient competence not merely to survive but to begin to participate in Canadian life and eventually attain full integration into Canadian society" (p. 15). The following is an example of a Global Outcome: "At the end of level 1 , learners should be able to follow simple ( $2-5$ word) verbal instructions and positive and negative commands/ requests (e.g., please stand up, give me, show me, right here, over there, repeat please ...)" (p. 24).

Canadian culture is also addressed through the description of the layout of topical units. It is explained that there are lists of items under the heading "classes may want to learn more about," which are lists "of sociocultural items that could facilitate the learners" integration into Canadian society and enhance communication ability" (p.9).

The introductory section of the guidelines also acknowledges the learners' cultures: "The themes, topics and the learning outcomes of these guidelines attempt to reflect the multiculturalism of Ontario. Learners may wish to participate in and contribute to this shared culture" (p. 11). It is not clear how the themes, topics, and learning outcomes reflect the multiculturalism of Ontario; nevertheless, the following recommendation is made:

In implementing these guidelines, the special position of LINC learners should be recognized and respected. As adults from other countries, they bring a rich cultural background to the language classroom. They have proficiency in other languages and prior life/learning experiences in other cultures that enable them to identify and express their own English language learning requirements. They have plans and aspirations for their lives in this new country. (p. 11)

Developing cultural awareness. Nothing is said in the introductory section about the depth to which culture might be explored or about developing learners' - or for that matter instructors'-cultural awareness. 
Empowering learners. The introduction to the guidelines states that "In dealing with [certain] issues in the classroom, it is important to distinguish clearly between what is law and what is opinion, and to emphasize that no one way of dealing with these issues is being endorsed" (p. 19). The ideas that (a) LINC instructors and providers are not necessarily authorities on what is right and wrong; and (b) it is acceptable to have different views on and approaches to dealing with issues are congruent with the aim of empowering learners.

There is also reference to the learners' first language. A description of LINC level 1 says that "some of the sociocultural items are too linguistically complex to deal with. But if learners require this information urgently, instructors can present the items using resources in the learner's native language. Print and even audio material can be obtained in learners' first languages, and cultural interpreters (volunteer or paid) are an invaluable resource in LINC programs" (p. 19). This kind of validation of learners' cultural and linguistic backgrounds is positive from a power relations perspective.

\section{Topical Units}

A series of topical units makes up the bulk of the LINC Curriculum Guidelines document. At each of the three LINC levels, there are 48 topical units (e.g., Dealing with Unemployment) under 12 thematic headings (e.g., Employment). Each topical unit consists of the following sections.

- lists of sociocultural items under the heading "classes might want to learn more about" (e.g., "Employment insurance and social assistance-rights, obligations, regulations, appeal procedures");

- lists of learning strategies under the heading "learners might find it useful to" (e.g., "Use repetition and rephrasing to clarify information");

- lists of performance outcomes (e.g., "By the end of this unit, the LINC 1 learner will be able to identify own and related occupations from photographs");

- lists of linguistic items relevant to the performance outcomes (e.g., "vocabulary related to occupation and job titles");

- sample tasks and activities (e.g., "field trip to local Canada Employment Center to identify signs, forms and computers").

Items relevant to culture tend to appear primarily in the list of sociocultural items. This list contains a total of 371 items, which are the same for each of the three LINC levels (see Appendix). Applying the analytic framework to the LINC topical units reveals the following information.

Balancing a focus on the learners' cultures with a focus on the L2 culture. It is interesting first to note the balance between items that refer to Canadian society or culture ( 328 items) and those that refer to the learners' cultures (43 
items). Perhaps more significant is that in 23 of the 48 topical units no items make reference to the learners' cultures.

Developing cultural awareness. None of the 371 items explicitly mentions values or beliefs. Of the 43 items that refer to learners' cultures, 37 refer to superficial cultural differences (e.g., cultural differences in policing), three refer to different cultural attitudes (e.g., toward medication), and three refer to cultural variation in people's roles (e.g., in the family). Although most of the sociocultural items could certainly be expanded in an effort to develop cultural awareness, little has been built in explicitly at the curriculum design level.

Empowering learners. From this perspective the picture may be more balanced. The items that refer to Canadian society or culture ( 328 items) can be divided into two categories: (a) those that deal with facts and conventions about Canadian life (227 items); and (b) those that deal with problems and solutions, as well as services and support new Canadians might find particularly useful (101 items). The latter appear to be relevant from an empowerment perspective. Also, there seems to be relatively consistent attention to both categories, as 32 of the 48 units contain sociocultural items from both categories.

Also relevant from a power relations perspective is the regular reference in the lists of learning strategies to L1 resources and the learners' rights to request those resources in various situations. Of the 48 topical units, 32 include one or more items that refer to L1 resources (e.g., asking for translations of materials or requesting interpretation). For example, in the unit on driving in Ontario, the first two items under the heading "learners might find it useful to," suggest that students (a) "study a drivers' manual in first language," and (b) "find a drivers' license center that offers tests in first language" (p. 30).

\section{Summary}

Analyzing the LINC Curriculum Guidelines by means of the Analytic Framework reveals that the LINC guidelines attend to Canadian society and culture through (a) sociolinguistic functions of English, and (b) sociocultural information intended to help LINC learners integrate into society. Attention to learners' cultures is less evident. Apart from isolated suggestions in the introductory section and a small proportion of material in the topical units, it has apparently been left to instructors whether they will find ways to include the learners' cultures in lessons and materials.

As for the development of cultural awareness, little in the guidelines suggests a close, critical look at the way things are done in Canada or the learners' native countries. Nothing is said about cultural beliefs or values, so it is again left to the instructor whether such a perspective will be taken in classes. 
Finally, from a power relations perspective, there is an attempt in the LINC Curriculum Guidelines to empower learners to be active, critical participants in society. References to L1 resources for learners are made in places in the introduction. The topical units include references to $\mathrm{L} 1$ resources as well as strategies for dealing with various social problems.

\section{Discussion}

An evaluation of the LINC Curriculum Guidelines based on these results would be inappropriate here because the primary purpose of this examination was to test the Analytic Framework for Culture in ESL Instruction. Nevertheless, the results may be of interest to LINC personnel. They may also be a basis for further exploration of the way culture is addressed in this important Canadian ESL program. From this perspective, research directions that might be worth exploring include (a) the match between curriculum guidelines and what actually occurs in classrooms, and (b) the perceptions of instructors and learners.

Is the proposed framework an effective tool for looking at culture in an ESL instructional context? In this case it was helpful in clarifying the place culture occupies in the LINC Curriculum Guidelines. However, this application of the framework raised important issues.

The first of these has to do with context. In an English as a foreign language context (e.g., students learning English in Japan), where classes tend to be culturally homogenous, learners may have little to learn from each other culturally. Therefore, cultural content and material often deals primarily with the L2 culture. In addition, the idea of empowering learners to be active participants in the L2 society may be largely irrelevant in that setting. By contrast, in the Canadian ESL context these matters appear relevant. First, the variety of cultures represented in a class may give the learners something to share with each other. Materials like the Tapestry series of textbooks (Wegmann, Knezevic, \& Werner, 1994) try to capitalize on this:

Many ESL books and programs focus completely on the "new" culture, that is, the culture the students are entering.... The Tapestry Program values all the cultures found in the ESL classroom. Tapestry students have constant opportunities to become "culturally fluent" in North American culture while they are learning English, but they also have the chance to think about the cultures of their classmates and even understand their home culture from different perspectives. (p. ix)

Also, in most cases the learners in an ESL setting are already participating in the L2 society, so learner empowerment is a relevant issue. The components of the proposed framework, then, may be more important in some instructional contexts than in others. 
The second issue has to do with goals of a course or program. The application of the proposed framework indicated that the development of cultural awareness receives minimal attention in the LINC Curriculum Guidelines. The development of cultural awareness, however, may be perceived as unrelated to the basic goal of the LINC program, which is "to help learners develop communicative competence in English in order to be able to participate more fully in Canadian society" (Citizenship and Immigration Canada, Ontario Region, 1997, p. 8). The analytic framework should be applied with consideration for course or program goals.

The third issue is the limitation of applying the analytic framework only to the curriculum guidelines of a program. In addition, the analytic framework needs to be applied to the goals of learners, instructors, and program funders, as well as to the reality of the classroom. For instance, if an instructor wishes to help learners become active participants in society, strategies and materials to empower learners may be evident in his or her instructional process.

\section{Further Research}

The analytic framework presented here may be a useful tool in seeking answers to the following research and development questions.

How do ESL teacher training programs address culture? It seems clear that culture is a significant component of the ESL teaching-learning process. From an instructor's perspective, then, teacher training may be most helpful when it includes components that deal with culture.

How are goals that are related to culture articulated in an ESL program curriculum? As suggested above, goals are probably relevant to the way culture is addressed in an ESL program. As a result, clear statements of such goals may be desirable.

How are cultural outcomes assessed in an ESL program? Outcomes related to the development of cultural awareness or learner empowerment may need to be assessed in a different way than other outcomes are (e.g., linguistic outcomes).

Do ESL programs as they are currently delivered provide sufficient cultural perspective? Should they be part of a broader package? For example, if an ESL program does not aim to develop cultural awareness or empower learners, perhaps this can be done through a more comprehensive program of assistance.

In what other instructional contexts might this framework be applicable? The context in which the proposed framework has been presented here is the ESL program for adult immigrants in Canada. It may be worth investigating different contexts (e.g., international students who are studying at Canadian universities and who require ESL support) to see how this framework might be helpful. 


\section{Conclusion}

The Analytic Framework for Culture in ESL Instruction provides a systematic analysis of a complex topic. In so doing it also draws attention to features of an ESL program or instructional process in a way that is largely ignored. The sample analysis done here indicates that the cultures of ESL learners receive relatively little attention in the LINC Curriculum Guidelines. Quintero (1994) points out that such a lack in a mainstream educational context would be unfortunate:

When learners' ways of understanding the world are not heard and accepted, everyone loses - the learners, who bring this knowledge with them to schools; the parents, who want to pass on cultural traditions but find themselves fighting both the school information and their children's perceptions of the value of their own cultural beliefs; and the teachers, who could be opening new worlds of exploration to child ren and themselves while providing a bridge between the culture of the school and the culture of the home. (p. 1)

This loss might occur in adult ESL classrooms when the cultures and background experiences of learners are not considered. It may be easy to get caught up focusing on the L2 culture, and trying to help learners to find ways to fit in. If this is done to the exclusion of the learners' cultures, however, a potentially rich teaching and learning resource may go unnoticed.

\section{Acknowledgments}

I would like to thank the following people for help in the preparation of this manuscript: the TESL Canada Journal reviewers and editors, J. Cummins, C. and B. James, R. Macksoud, and H. Kildare.

\section{The Author}

Mark James is a doctoral student in the second language education program at the Ontario Institute for Studies in Education of the University of Toronto (OISE/UT).

\section{References}

Auerbach, E.R. (1995). The politics of the ESL classroom: Issues of power in pedagogical choices. In J.W. Tollefson (Ed.), Power and inequality in language education (pp. 9-33). Cambridge, UK: Cambridge University Press.

Banks, J.A. (1998). Approaches to multicultural curriculum reform. In E. Lee, D. Menkart, \& M. Okazawa-Rey (Eds.), Beyond heroes and holidays (pp. 74-75). Washington, DC: Network of Educators on the Americas.

Campbell, C., \& Kryszewska, H. (1992). Learner-based teaching. Oxford, UK: Oxford University Press.

Citizenship and Immigration Canada, Ontario Region. (1997). LINC Curriculum Guidelines, 1997. Toronto, ON: Author.

Condon, J.C., \& Yousef, F.S. (1975). An intr duction to intercultural communication. Indianapolis, IN: Bobbs-Merrill. 
Cummins, J. (1996). Negotiating identities: Education for empowerment in a diverse society. Ontario, CA: California Association for Bilingual Education.

Gardner, R.C. (1985). Social psychology and second language learning: The role of attitudes and motivation. London: Edward Arnold.

Gardner, R.C., \& Lambert, W.E. (1959). Motivational variables in second language acquisition. Canadian Journal of $P_{\text {sychology, }}$ 13, 266-272.

James, M.O. (1987). ESL reading pedagogy: Implications of schema-theoretical research. In J. Devine, P.L. Carrell, \& D.E. Eskey (Eds.), Research in reading in English as a second language (pp. 175-188). Washington, DC: Teachers of English to Speakers of Other Languages.

Quintero, E. (1994). Valuing diversity in the multicultural classroom. ERIC Digest. (Adjunct ERIC Clearinghouse for ESL Literacy Education, Washington, DC, Nov. 1994). (ERIC Document Reproduction Service ED 378 846)

Scanlon, J. (1998). Developing cultural awareness in the language classroom. In J. Kahny \& M. James (Eds.), Perspectives on secondary school EFL education (pp. 75-79). Odawara, Japan: Language Institute of Japan.

Statistics Canada. (1991). Immigration and citizenship. Ottawa, ON: Ministry of Industry.

Stern, H.H. (1983). Fundamental concepts of language teaching. Oxford, UK: Oxford University Press.

Wegman, B., Knezevic, M.P., \& Werner, P. (1994). Culture connection. Boston, MA: Heinle and Heinle.

\section{Appendix: Sociocultural Items from Two Example Units in LINC Curriculum Guidelines}

\section{Unit-Banking}

Students will learn about the following:

- Automated Banking Machiness, including related rules and security precautions

- Personal Identification Numbers (PIN)

- The purpose of different types of bank accounts, such as checking, savings and joint

- Different types of banking services, such as RRSPs, mortgages, loans and safety deposit boxes

- Bank credit cards, including how to get a card and rules about interest

- Bank statements and records

- Notifying the bank about the loss of credit card, banking card, or chequebook

- Personal identification documents, such as driver's license and SIN card

- Rules for cheque writing (NSF cheques, corrections)

- Different types of banking institutions, such as credit unions

- Due dates for bills, loans and mortgages

- Income tax, including using T1

\section{Unit-Police}

Students will learn about the following:

- Different police forces, such as OPP, RCMP and local police forces 
- The role and responsibilities of police in Ontario including helping to find missing persons, dealing with domestic disputes

- Informing the police of lost or stolen identification documents, including driver's license

- Reporting accidents on the street

- The proper uses of 911 and other emergency numbers

- Cultural differences in policing 